\title{
Commitment as a Strategy for the Adoption of an Environmental Management System: The Case of a Public Research Institution
}

\author{
Silva Maria C. Cavalcante, Andrade D. Alves \\ Institute of Energy and Nuclear Research, São Paulo, Brazil \\ Quishida Alessandra \\ Federal Institute of Education, Science and Technology of São Paulo, São Paulo, Brazil
}

\begin{abstract}
The objective of this paper was to examine, through a Problem Structuring Methods (PSMs) cognitive map, the possible uncertainties, complexities, and conflicts related to the commitment element, as a consequence of the environmental management adoption, through the implementation of an Environmental Management System (EMS). It was, also, proposed a measurement model of this mentioned behavior to be validated in future studies, in order to measure the commitment of all civil-service employees involved in the new management, before adopting this given system. The commitment to be analyzed through this model is divided into two components: affective and normative. The research was done with 15 managers of a Federal Public Institution, located in the state of São Paulo, Brazil, and the data that compose the cognitive map were obtained through a face-to-face interview, from May to November 2015, besides group meetings with the aforementioned managers, from December 2015 to March 2016. The results of the cognitive map analysis demonstrated the necessity to investigate the commitment factor, when there is the intention of adopting the EMS. It was, also, inferred that the suggested model, will be validated in longitudinal studies.
\end{abstract}

Keywords: environmental management system, organizational commitment, SODA cognitive maps

To adopt procedures that favor the preservation of the environment, as well as to use natural resources in a sustainable way, is now imperative in the productive process of both private and public organizations. Compliance with environmental laws restricting the emission of pollutants, waste disposal, noise emission, and the exploitation of natural resources is global conjuncture that organizations will have to consider in all their business actions.

The adoption of these conjunctures, with the objective of minimizing the environmental impact of economic activities, may be facilitated through actions well seen by society, resulting in a better image in the market and better commercial relations reflected, for example, in credit allowance for financing projects focused on activities that favor the environment.

Corresponding author: Silva Maria C. Cavalcante, Ph.D., assistant in science and technology, Institute of Energy and Nuclear Research, São Paulo, Brazil; research field: people management.

Andrade D. Alves, Ph.D., research at Institute of Energy and Nuclear Research, professor of University of São Paulo, São Paulo, Brazil; research fields: thermohydraulic, human factors, nuclear security.

Quishida Alessandra, Ph.D., professor, Federal Institute of Education, Science and Technology of São Paulo, São Paulo, Brazil; research field: people management for innovation. 
According to this reasoning, several organizations have adopted a set of interrelated administrative and operational activities to address current environmental problems or to prevent their emergence. In this set of activities, called Environmental Management System-EMS, by Barbieri (2007), the commitment element comes first, according to this author, with its effectiveness by the organization leaders.

The commitment, as well posed by Horn and Cerutti (2013), Costa (2014), and Paiva, Dutra, and Luz (2015) has the power to face the necessary changes that require not only the awareness of its importance, but also, the will of the individuals involved, so that they commit to the new objectives to be proposed by the organization. The present paper seeks to characterize it as a "strategy" for the adoption of business management focused on the environmental issue.

Preceding the investigation of the organizational commitment, in relation to the adoption of an EMS, it will offer the anticipated knowledge of the behavior of the actors to be involved in the new type of management, providing the development of interrelated administrative and operational activities by committed people, when current environmental problems are approached or in their prevention.

In this regard, this study sought to examine, through SODA (Strategic Options Development and Analysis) cognitive map, possible uncertainties, complexities, and conflicts, aimed at the commitment element, when adopting environmental management through the implementation of an EMS by 15 managers of a Federal Research Institute, located in the city of São Paulo, Brazil.

Taking into account that the implementation of an EMS implies the integration of the largest number of participants interested in dealing with environmental issues, involving the elements: establishment of an environmental policy; assessment of current and future environmental impacts; plans for setting goals and targets; instruments for monitoring and evaluating the planned actions and the actual performance of this system as a whole; besides the relevant element of commitment, the institution investigated as well as the other organizations, look for alternatives that may provide favorable conditions to achieve satisfactory and effective results derived from EMS employment.

The relevance of this behavior is identified by its power to face changes that require not only awareness of the importance of adopting a management system focused on the environment, but also, by the will of individuals to be involved to compromise with the proposed new objectives.

The study was done through a face-to-face interview with 15 managers of a Federal Public Research Institution, located in the state of São Paulo, Brazil and the answers obtained comprised SODA cognitive map, with the objective of investigating how the commitment element is approached, when the EMS is intended to be adopted by the mentioned institution and how such knowledge will help in the characterization of this element as a strategy for the adoption of an EMS.

The objective of this study was to examine the potential uncertainties, complexities, and conflicts, related to the element of commitment, from the adoption of environmental management through implementation through Problem Structuring Methods (PSMs) of an EMS. It was also evaluated through the inferences obtained during the analysis, the importance of the commitment, establishing the behavior cited as strategy when adopting an EMS.

Thus, an investigation about the supposed relationship between the commitment of the employees and the adoption of an EMS, which enables the creation of an instrument for measuring the degree of commitment by the employees of the institution investigated was necessary, given the importance of this behavior and the scarcity of theoretical research in Brazil covering the subject of this study. It should be pointed out, however, 
that in the last 20 years, the institution under investigation has been scrapping human resources, since the number of retired employees has far exceeded the number of new hired employees by tender, what makes the present work even more relevant.

In this context, employees to be involved in a differentiated management should be committed to the profound changes of paradigms, since there is no competitiveness in terms of profitability because it is a Public Institution, but there is the requirement to excel in its area, with the major objective of raising financial resources and being recognized in its competence. Consequently, the organization will achieve a high status in the national and international technical-scientific context (research, production, and training of human resources), indispensable elements for the fulfillment of the institution mission. "Our commitment is to improve the quality of life of the Brazilian population, producing scientific knowledge, developing technologies, generating products and services and training human resources".

Certainly, there is not a unique way to manage. The organization, by its dynamics, will always be looking for different solutions to deal with the complexity of problems arising from its own performance. Knowing, in advance, the commitment of its most important asset when adopting a differentiated management, here the Environmental Management, will contribute to the achievement of the related objectives and policies.

\section{Theoretical Background}

\section{Environmental Management System}

EMS is the second set of organizational responsibilities, procedures, processes, and means that are adopted for the implementation of an environmental policy, in a given organization, according to Dias (2011). The author states that this method leads the organization to reach and remain in operation in accordance with the established standards, achieving the objectives defined in its environmental policy.

The EMS requires, according to Barbieri (2007), formulation of guidelines and definition of objectives, plus the coordination of activities and the evaluation of results.

The EMS management model is based on five principles (Dias, Martins, Prestes, \& Silva, 2012), which have to be obeyed by the companies:

(1) Knowledge of what should be accomplished, ensuring the commitment to the EMS and defining the environmental policy;

(2) Development of an action plan aimed at meeting the requirements of the environmental policy;

(3) Ensured conditions for the fulfillment of environmental objectives and goals, implementing the necessary support tools;

(4) Accomplishment of periodic qualitative and quantitative assessments of the company environmental compliance;

(5) Review and improvement of the environmental policy, with objectives, targets, and actions implemented to ensure the continuous improvement of the company environmental performance.

The environmental management term is quite broad and it is often used to designate environmental actions in certain geographic spaces, such as: environmental management of river basins, environmental management of parks and forest reserves, management of environmental protection areas, environmental management of biosphere and others (Dias et al., 2012).

ISO 14001 standard, published in Brazil by the ABNT (Brazilian Association of Technical Standards), proposes a management model that intends to be environmentally responsible; committed to compliance with 
legislation, continuous improvement, and pollution prevention and based on the PDCA continuous improvement cycle described in Figure 1.

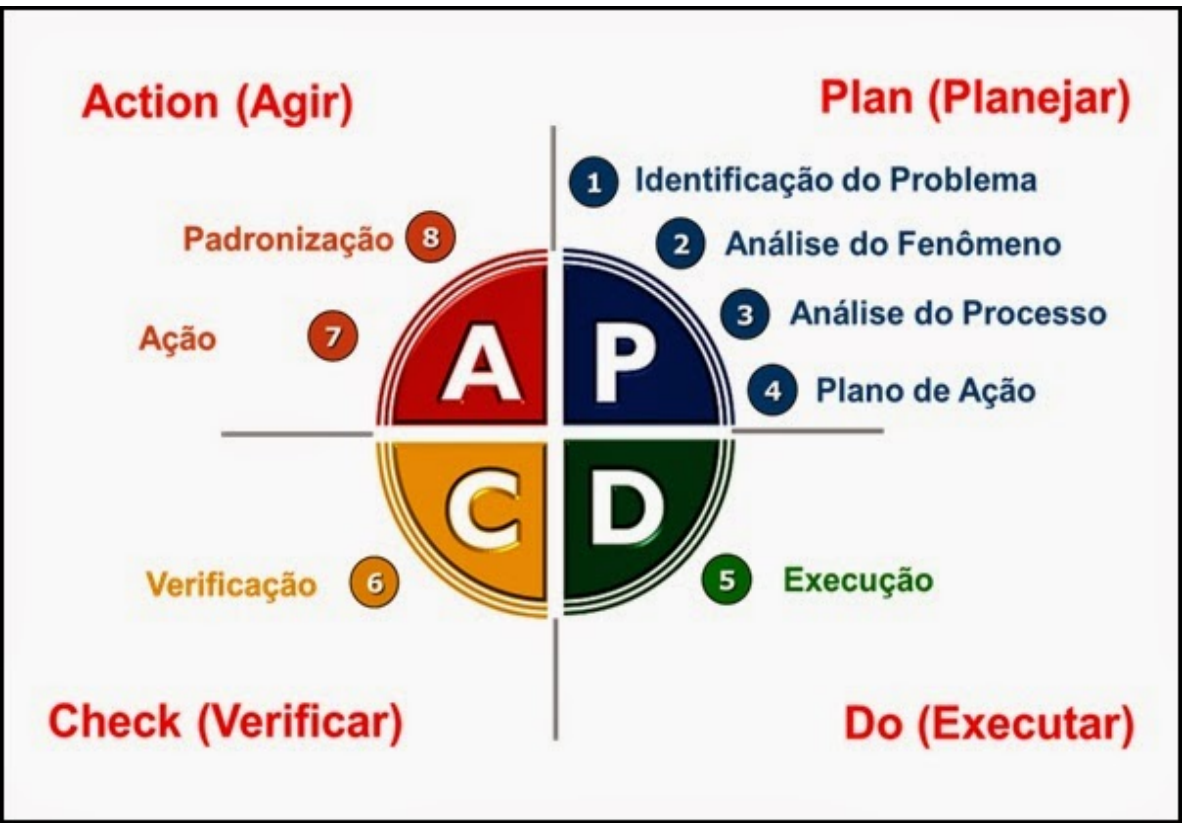

Figure 1. PDCA cycle. Source: Portal Administração. Available in: http://www.portal.administração.com. Access on: August 1, 2016.

\section{Organizational Commitment - Conceptual Strands}

This relevant topic in sociological discussions, "sociologists use the concept of commitment when they are trying to account for the engagement of people who act on consistent lines of activity" (Becker, 1960, p. 34), has three predominant conceptual approaches: affective, instrumental, and normative. These three approaches have been addressed in some studies separately, such as the affective focus (Mowday, Steers, \& Porter, 1979; Mowday, Porter, \& Steers, 1982), or in multidimensional models, such as the three-component conceptualization model of organizational commitment and the occupational approach, by the researchers Meyer and Allen (1997). This study will present the one-dimensional approaches, named by the mentioned authors as affective, instrumental, and normative.

Affective:

This approach dominated the literature of organizational commitment for a longer time, starting with the research developed by the team of Lyman Porter (Mowday et al., 1979; Mowday et al., 1982). This line of work, despite recognizing the existence of a behavioral chain to define commitment (Medeiros, 2003), assumes commitment from an attitudinal perspective. For authors of this type of commitment, it represents more than just passive loyalty to the organization, involving an active relationship in which the employees place something of themselves in search of the well-being of the organization (Tamayo, 2005).

Instrumental:

The instrumental focus of organizational commitment derives from Becker's (1960) studies. The author traces instrumental commitment as an individual's tendency to engage in consistent lines of activity. This commitment is also called "side bet", which may be translated as lateral exchanges, assuming several other labels, as observed by Medeiros (2003), such as calculative and continuation. The individuals remain in the 
company due to the costs and benefits associated with their exit, which would be the lateral exchanges (Becker, 1960).

It refers to the willingness of the employees to remain in the organization in order not to lose their personal investments on it. Tamayo (2005) argued that labor market alternatives are, also, an important source of instrumental commitment and that, under this perspective, the commitment proves to be a consequence of the employee's necessity of the organization.

Studies such as Allen and Meyer (1990) find a high correlation among instrumental commitment, retirement plans, and investments made by employees. Several studies empirically show correlations between instrumental impairment in indicators related to investments made by individuals at work and also with work alternatives (Bastos, 1997; 1994; Medeiros, 2013).

Normative:

The normative component of commitment was identified after the work of McGee and Ford (1987), examining the psychometric properties of the scales developed by Meyer and Allen (1984) to measure affective and instrumental commitment.

McGee and Ford (1987) found three distinct factors: the first formed with affective scale indicators; the second formed by indicators that showed the existence of few alternatives of job for the employee; and the third factor, bringing together indicators that reflected the commitment based on the personal sacrifice associated with leaving the organization. The contributions of McGee and Ford's (1987) work were very important in the commitment literature and it was considered a milestone in the commitment process (Medeiros, 2003).

Wiener (1982) conceptualized commitment as "the totality of normative pressures internalized to act on a path that meets organizational goals and interests" (Wiener, 1982, p. 421).

The author emphasizes that accepting organizational values and goals represents a form of control over people's actions that he calls normative-instrumental approach. According to Wiener (1982), individuals engaged in a normative approach exhibit certain behaviors because they believe that it is right and moral to do so. This feeling of obligation originates from normative controls of the organization, such as missions, norms, and regulations, among others (Tamayo, 2005).

Medeiros (2003) pointed out that the normative pressures come from the company culture, imposing action and behavior in the organization and that this normative vision of commitment suggests a focus centered on normative controls by the organizations, such as norms and regulations, or also, as a strong and widespread mission within the organization.

Measurement of normative commitment was tested quite simply by Allen and Meyer (1990). The normative commitment was evaluated through three indicators. Respondents were asked to what extent they felt that an individual should be loyal to their organization; whether they should make sacrifices for the benefit of the organization; and whether they should not criticize the organization.

These two authors, whose measurement model is served as a basis for the elaboration of the commitment measurement instrument proposed in the present study, define the commitment in three components:

Affective: the commitment as an attachment or involvement, where the identification with the company occurs. "Employees with strong affective commitment remain in the organization because they want to" (Meyer \& Allen, 1997);

Instrumental: perception of commitment as associated costs in leaving the organization. "Instrumentally committed employees remain in the company because they need it" (Meyer \& Allen, 1997); 
Normative: commitment as an obligation to remain in the organization. "Employees with normative commitment remain in the company because they feel they have this obligation" (Meyer \& Allen, 1997).

\section{Methodology}

The research initiated through an exploratory survey seeking primary data that helped in the formulation of the commitment measurement instrument in relation to the adoption of an EMS, here is proposed.

The commitment, both in the affective and in the normative approaches, has the power of facing the necessary changes that require not only the awareness of their importance, but also, the will of the involved individuals, to be committed to the new proposed objectives.

The random sample composed of 25 managers of the institution was taken from the population of 57 of these professionals who, according to the internal survey, pointed out their intention of remaining in the institute for, at least, another 10 years.

The body of employees is constituted of federal civil servants, governed by the Unique Legal Regime (regime differentiated from that conducting private contract), with average age of 50 years and most of them having the possibility of retirement at any time, considering that they have already acquired this right.

Out of the 25 selected managers, 10 chose not to participate in the survey, with 15 participants left. It should be noted that the institution researched, like any other Public Institution in Brazil, has faced the lack of replacement of workers through public tenders, for more than two decades, as already mentioned, what has gradually reduced its staff.

Data collection was done through a face-to-face interview conducted between May and November of 2015 and group meetings, with the aforementioned managers, from December 2015 to March 2016, using cognitive mapping for analysis. The choice of this method was based on the curiosity concerning the status of the commitment, as the most relevant behavior within the set of elements required by an EMS.

The cognitive mapping was carried out through the SODA, which, as Morita (2013) stated, has the rigor and formalism derived from Kelly's (1955) personal construct theory, which proposes the understanding of how human beings look for meanings for their world, seeking to manage and control it.

The constructs derived from the cognitive mapping expressed the ideas and actions of the interviewees concerning the commitment to the adoption of an EMS. These constructs, reaching a maximum of 200, were transcribed using the interviewees' own words, thus conferring the identity between the map and the interviewee.

The elaboration of these maps (individual and group) occurred with the opening to the expression of restlessness and ideas; with the demonstration of concern about anxiety and threat; with the recognition of the uniqueness of each member and the discussion of collective doubts, as established in the literature (Nicolella, Marques, \& Skorupa, 2004).

Out of the 200 constructs derived from the cognitive mapping, 25 constituted the definitive cognitive map of the group, allowing the configuration of the commitment measurement instrument as for the adoption of an EMS. Referred instrument addresses the two components: affective and instrumental.

The analysis of the data that comprise the cognitive map considered the structure: tails, heads, strategic option, and dominants and proceeded to the construct domain analysis, where the mentioned domain, as stated by Morita (2013), is similar to a knot inserted in a signalized digraph, whose connections are made by means of guided arcs, which cover the guided arcs coming from the construct, as well as, the arcs that reach it. 


\section{Discussion of Results}

The fundamental "tail" construct of the present study, known as the primary cause of the mapping result of the interviewees' thoughts and ideas about the problem proposed in this study, is pointed as the main pole of the construct, "there is a lack of awareness of the importance of working under an Environmental Management" and as a secondary pole, "maximizing actions that favor a continuous environmental education". This construct had 11 arcs starting from it, concluding its influence in the other constructs.

From this construct, other constructs have been developed: It is necessary to propagate the commitment of the institution managers in relation to the adoption of an EMS; there is a lack of elucidation regarding the necessary adoption of an EMS in the institution, so it should promote explanation; there is a lack of specific knowledge for the implementation of the EMS, so it should hire advisory services; it is missing to meet companies with consolidated Environmental Management, so it should promote visits to companies where the Environmental Management is consolidated; there is the absence of partnership with companies that have a successful EMS, so it should propose partnerships.

It is missing to divulge, in the scope of the institution, how the activities of the area are developed concerning the environment, so it should propagate dissemination; there is resistance in relation to the participation of third parties in the actions that lead to the adoption of an Environmental Management, so it should propagate what is permissive; it is not clear enough about the obligation of the top management as to directing the institution's essential actions in the social field, so it should propagate the obligation; it lacks to know and respond to society's expectations regarding the way in which the institution's activities are carried out, so it should investigate expectations.

The following constructs have been placed: It is still necessary to identify the level of incorporation of the institution's values by its members and adopt actions that clarify the importance of the institution's values to be incorporated in the workers' routine; there is the absence of awareness about the EMS importance, so it should promote this knowledge; it is necessary to disseminate the possibilities that the institution policies already have in relation to the adoption of an Environmental Management and propagate the policies; it is necessary to disseminate the commitment of the institution managers in relation to the adoption of an EMS and make the commitment known; there is a lack of explanation regarding the necessary adoption of an EMS in the institution, so it should promote the elucidation.

There is the absence of specific knowledge for the implementation of the EMS, so it should hire specialized advisory services in the conduction of the EMS; there is a necessity of disseminating, in appropriate language to the supporting workers and/or outsourced employees, the research developed in the institution and promoting the propagation; there is a lack of awareness of the importance of working under the Environmental Management, so it should maximize actions that favor a continuous environmental education; there is a lack of legislation regarding sustainable government policies.

It is necessary to participate in forums, congresses, and seminars dealing with sustainable government purchases; there is a necessity of identifying the institution procedures when identifying servants' indifference to changes and divulging mechanisms used by the institution when noticing servants' indifference to changes; it is necessary to identify the behavior of the workers in relation to the adoption of an EMS and search mechanisms that lead to the identification of the mentioned behavior.

The construct is identified as "strategic option", whose main pole indicates the "unavailability of adequate 
structure and human and financial resources for the implementation of an Environmental Management System" and its secondary pole, "raising resources with competent entities, through reports about the need for such adoption, plus the implications of its non-attendance", indicates the immediate influences that precede the "head" construct, meaning that through this construct the conduction of constructs to the desired goal occurs; there is the vital need for elements that favor and lead, in a promising way, to the implementation of an EMS.

The constructs that were originated from the "strategic option" construct were: It is missing to meet companies whose Environmental Management is consolidated, so it should promote visitation to companies where the Environmental Management is consolidated; It is necessary to disseminate and propagate, in appropriate language, to the supporting workers and outsourced employees, the research developed in the institution; It lacks to disclose, in the scope of the institution, how the activities of research are developed, concerning the environment, so it should propagate; It is necessary to diffuse and propagate the relationship of the institution with the external clients.

The constructs that focused on the "strategic option" construct were: It is missing to identify actions that maintain the values of the institution, continuously, incorporated into the activities of the employees and search for the dissemination of the institution values in the activities of the workers through stimuli that lead them to contribute by themselves; It is missing to explain the necessary adoption of an EMS in the institution, so it should promote clarification; There is the absence of actions that allow the participation of outsourced employees in the implementation of an EMS, so it should adopt initiatives that promote the participation of outsourced employees in the implementation of an EMS; There is a lack of specific knowledge for the implementation of the EMS.

It is necessary to contract advisory services specialized in the conduction of the EMS; It is missing to disseminate, to the employees of the area and outsourced employees, the products and services available to the society by the institution, so it should propagate the products and services provided by the institution. There is the absence of legislation concerning sustainable governmental acquisitions and participation in forums, congresses, and seminars that deal with sustainable government purchases theme.

It was, also, understood that people to be involved in the implementation of an EMS should have the behavior representing more than the simple passive loyalty to the organization, when adopting an EMS, since it involves an active relationship in which the employees place something of themselves in the quest of the goals proposed by the mentioned management.

\section{Conclusions}

This paper, using SODA cognitive map, proposes to answer questions raised on how the commitment element is treated when there is the intention of adopting an EMS, in a Federal Public Research Institution, located in the state of São Paulo, Brazil and how such knowledge may assist in the characterization of this element as a strategy for the adoption of the mentioned system.

The analysis of this cognitive map facilitated the achievement of the proposed objectives by examining, through the methodology PSMs, the possible uncertainties, complexities, and conflicts, related to the commitment element, derived from the adoption of the environmental management, through the implementation of an EMS. The analysis, also, enabled to structure a measurement model of the commitment seen as a strategy for the adoption of the mentioned system. 
The constructs that formed the cognitive map with group interaction, pointed out the unavailability of an adequate structure or human and financial resources for the implementation of an EMS, as well as the understanding of raising resources from competent entities, through reports stating the necessity to adopt this policy and the implications derived from its non-application.

This position makes evident the objective demonstrated in the map, that is, the necessary identification of elements that lead to the implementation and maintenance of a successful EMS, since the recognition of deficient awareness of the importance of working under an Environmental Management becomes clear, evidencing the necessity to maximize actions favoring a continuous environmental education.

The measurement model will provide the knowledge of the commitment degree to be involved when adopting an EMS, implying the knowledge of the behavior of civil-service employees, who will participate in the procedures and processes related to the implementation of an environmental policy in the institution.

The referred behavior was seen as the level of psychological link of an individual with the organization and this link has implication in the employee's resolution to remain in the institution with the new form of management- the Environmental Management.

When designing the commitment measurement instrument, it was, also, concluded that it was necessary to identify the public servants to be involved in the proposed management, that is, in the development of interrelated administrative and operational activities covering present environmental problems or preventing their occurrence, with these civil employees showing clearly, through their behavior, that they believed their involvement was right and moral to occur.

This instrument proposes to analyze the commitment under two factors: affective, which has the commitment as an attachment, as an involvement, with identification with the institution proposal. "Employees with strong affective commitment maintain commitment to new management goals because they want to" (Meyer \& Allen, 1997); the second factor, normative, occurs when the commitment is seen as an obligation to remain in the organization, when the environmental management is adopted. "Employees identified with this behavior remain in the company because they feel they have this obligation" (Meyer \& Allen, 1997).

In this sense, the commitment may be used as a strategy for the successful adoption of an EMS, since it takes into consideration the relevance of the totalities of the individuals in the organizations and not only segments, such as the senior executives or operational personnel.

However, the requirement for validation of the proposed instrument through longitudinal studies is emphasized, given the possibility to describe administrative elements over time by this type of study, allowing their mapping so that trends may be observed.

\section{References}

Allen, N. J., \& Meyer, J. P. (1990). The measurement and antecedents of affective, continuance and normative commitment to the organization. Journal of Occupational Psychology, 63, 1-18.

Associação Brasileira de Normas Técnicas. (2002a). NBR 6023: Information and documentation: References-elaboration. Rio de Janeiro: ABNT.

Associação Brasileira de Normas Técnicas. (2002b). NBR 10520: Information and documentation: Citations in documents: Presentation. Rio de Janeiro: ABNT.

Associação Brasileira de Normas Técnicas. (2003). NBR 6024: Information and documentation: Progressive numbering of sections of a written document: Presentation. Rio de Janeiro: ABNT.

Barbieri, J. C. (2007). Corporate environmental (2nd ed.). São Paulo: Saraiva.

Barbieri, J. C., \& Simantob, M. A. (2007). Sustainable innovative organizations. São Paulo, Brazil: Atlas. 
Bastos, A. V. B. (1994). Commitment at work: The structure of the worker's links with the organization, the career and the union. Thesis of doctorate, University of Brasília, Brasília, DF, Brazil.

Bastos, A. V. B. (1997). Commitment at work: The paths of research and the theoretical-methodological challenges. In Organizations and culture. São Paulo, SP, Brazil: Editores Associados.

Bastos, A. V. B. (2000). Patterns of commitment to the profession and to the organization: The impact of personal factors and the nature of work RAUSP. Revista de Administração, 35(4), 48-60.

Bastos, A. V. B., Brandão, M. G. A., \& Pinho, A. P. M. (1996). Organizational commitment: Exploring this concept among servers of university institutions. Proceedings from Annual Meeting of the National Association of Graduate Programs in Administration, Rio de Janeiro, v. 9, pp. 289-310.

Becker, H. S. (1960). Notes on the concept of commitment. American Journal of Sociology, 66, 32-42.

Costa, F. M. (2014). Organizational commitment: Bases for a procedural approach. Psicologia: Teoria e Pesquisa, 30(3), 329-337.

Dias, R. (2011). Environmental management (2nd ed.). São Paulo: Atlas.

Dias, V. L. N., Martins, J. D. B., Prestes, L. D., \& Silva, R. (2012). Environmental education. Retrieved from http://www. historia.art.br/arquivos

Horn, J., \& Cerutti, B. B. (2013). Organizational commitment: A case study with the sales team of a beverage distributor in the Taquari Valley/RJ. Revista Destaques Acadêmicos, 5(1), 77-92.

Kelly, G. A. (1955). A theory of personality: The psychology of personal constructs (vol. 1). London, UK: Norton.

McGee, G. W., \& Ford, R. C. (1987). Two (or more?) dimensions of organizational commitment: Reexamination of the affective and continuance commitment scales. Journal of Applied Psychology, 72(4), 638-641.

Medeiros, C. A. F. (2003). Organizational commitment: A study of their relationships with organizational characteristics and performance in Brazilian companies. PhD thesis, Faculty of Economics, Administration and Accounting, University of São Paulo, São Paulo, Brazil.

Meyer, J. P., \& Allen, N. J. (1984). Testing "side-bet theory" of organizational commitment: Some methodological considerations. Journal of Applied Psychology, 69(3), 373-378.

Meyer, J. P., \& Allen, N. J. (1997). Commitment in the workplace: Theory, research and application. Thousand Oaks: Sage Publications.

Morita, T. (2013). SODA expanded cognitive maps: Prescription of a method to articulate attitudes, behaviors and cognitive sequences to SODA maps. Thesis of doctorate, School of Business Administration of São Paulo, Getúlio Vargas Foundation, São Paulo, Brazil.

Mowday, R. T., Porter, L. W., \& Steers, R. M. (1982). Employee organization linkages-The psychology of commitment, absenteeism and turnover. New York: Academic Press.

Mowday, R. T., Steers, R. M., \& Porter, L. W. (1979). The measurement of organizational commitment. Journal of Vocational Behavior, 14, 224-247.

Nicolella, G., Marques, J. F., \& Skorupa, L. A. (2004). Environmental management system: Theoretical aspects and analysis of a set of companies from the Campinas region. Campinas, SP, Brazil. Documentos 39, EMBRAPA.

Paiva, K. C. M., Dutra, M. R. S., \& Luz, T. R. (2015). Organizational commitment of call center workers. Revista de Administração, 50(3), 310-324.

Silveira, V. N. S., \& Miranda, D. L. A. (2011). People management strategy and approaches normative: A conceptual analysis in the context of management people. Proceedings from EnANPAD-XXXV ANPAD Meeting.

Tamayo, A. (2005). Organizational values and affective commitment. Revista de Administração Mackenzie, 6(3), 192-213.

Wiener, Y. (1982). Commitment in organizations: A normative view. Academy of Management Review, 7, 418-428. 